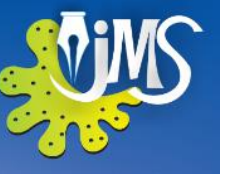

\title{
Life Cycle and Fixed Portfolio Allocation Strategies: \\ A Performance Comparison for Emerging Market Pension Funds
}

\author{
${ }^{1}$ Ajantha Sisira Kumara and ${ }^{2}$ Wade Donald Pfau \\ ${ }^{1}$ Department of Public Administration, University of Sri Jayewardenepura, Sri Lanka \\ ${ }^{2}$ American College of Financial Services, Pennsylvania, USA
}

\begin{abstract}
This study compares the performance of various fixed and lifecycle portfolio strategies for the accumulation phase of retirement planning in emerging market countries. With an expected utility framework and a bootstrapped Monte Carlo procedure, we find that the majority of emerging market investors with varying attitudes toward risk can maximize their expected utility by using lifecycle strategies instead of fixed allocation strategies. Most commonly, emerging market investors maximize expected utility with a lifecycle strategy using a 30 percent average equity exposure, though the results vary among countries.
\end{abstract}

KEYWORDS: Pension funds, portfolio strategies, emerging markets 


\section{INTRODUCTION}

The financial market turmoil in 20082009 has reminded policy makers of the uncertainty of returns on retirement savings in funded systems and in defined-contribution pension plans. Investment strategies as well as contribution amounts play a pivotal role in determining retirement income for such pension plans. There is a growing consensus that lifecycle strategies, with decreasing risk exposure as the individual ages, are better than fixed asset allocation strategies in delivering adequate retirement benefits from funded pension plans with a reasonable amount of risk. With lifecycle strategies, the investment portfolio gradually shifts over time to less risky assets as the target date approaches. Fullmer \& Tzitzouris (2014) emphasize that there are two competing goals to be achieved when selecting glide paths for defined contribution pension plans. They include creation of sufficient level of lifetime income over the course of retirement and reduction of the risk of capital loss during retirement. Their Monte-Carlo simulation exercise concludes that the glide paths with relatively higher equity exposure are capable of generating sufficient and consistent income to replace pre-retirement income. In contrast, glide paths with lower equity exposure reduce the risk of capital loss near retirement.

Burtless (2010) shows that lifecycle strategies provide a major advantage of lessening the variation in replacement rates for US retirees. By employing an expected utility framework, Pfau (2010) demonstrates that conservative investors may favor lifecycle strategies over fixed allocation strategies. Later, Pfau (2011) confirms these findings by comparing the performance of fixed strategies, lifecycle strategies, and contrarian or reverseglide path strategies with U.S. economic data, arguing that long-term savers with a reasonable amount of risk aversion would enjoy higher expected utility from using lifecycle strategies. On the other hand, Basu \& Drew (2009) argue that contrarian strategies which increase equity holdings near retirement would provide a higher expected terminal wealth for investors than lifecycle strategies. They argue that this results from "the portfolio size effect", which explains how lifecycle strategies reduce stock allocations near retirement when the portfolio size is the largest, which deprives the investor from earning high absolute returns. As discussed by Viceira (2010), lifecycle pension funds are more appropriate investment strategies for those whose labor income stream is relatively steadier. They further found that investors with low risk tolerance are likely to be better off with such strategies. Their simulation results confirm that keeping two lifecycle funds combining a more aggressive one with a more conservative one will enhance the overall welfare of investors. In contrast, Schleef \& Eisinger (2011) argue that lifecycle asset allocation strategies do not provide adequate portfolio risk protection in terms of maximizing the probability of reaching a particular wealth accumulation target. This, however, assumes that investors are risk neutral, or at least that they are not concerned by how much their wealth may fall below the target. Basu et al. (2014) recently confirm the same argument showing that the lifecycle strategies have not become the best strategies if we aim for a particular wealth threshold. Their analysis has justified that the portfolios with constant exposure to equities perform better than lifecycle strategies if we aim for a wealth threshold. Also, the funds with conditional switching of assets are also proven to be better than lifecycle strategies in case of an increasedwealth threshold.

The majority of literature is from the US and other advanced countries as the studies of this nature are scarce with regard to emerging market countries. Accordingly, the objective of this study is to compare the performance of fixed portfolio strategies with lifecycle portfolio strategies for 25 emerging market pension funds assuming investor risk aversion and diminishing marginal returns from wealth. Emerging market pension funds and investors are increasingly 
relying on advanced funding for retirements and are searching for better tradeoffs between risks and returns for portfolio strategies. To avoid focusing only on the distribution of retirement wealth or the probabilities of reaching certain fixed wealth accumulation goals, we use a utility-based approach, which permits us to assess how a retiree evaluates portfolio performance while taking into account risk aversion. Our simulation results justify the implementation of lifecycle strategies for retirement savers in emerging markets.

\section{METHODOLOGY}

In order to compare the performance of investment strategies on the basis of their expected utility, we employ the bootstrap Monte Carlo simulation procedure for a common hypothetical worker in each country. We assume that the common worker starts a 40-year career with an annual gross salary of 100 in each country's local currency. Salary grows annually by one percent in real terms. The worker saves 10 percent of his gross salary in his retirement savings account at the end of each year over 40 years. We further assume that there will be an annual administrative fee of 0.3 percent charged to the portfolio. Income from assets is assumed to be reinvested without deducting for income taxes. The portfolio is rebalanced at the end of each year to maintain the targeted asset allocation.

For each country, we consider 11 fixed asset allocation strategies for two domestic assets by varying each asset in 10 percentage point increments from zero to 100 percent. The fixed portfolio strategies are coded so that we can identify the asset mix of each strategy. For instance, the strategy "F100/0" maintains a 100 percent fixed allocation to equities and zero percent fixed allocation to bank deposits over a 40-year career path. These fixed allocation strategies will be compared to eight lifecycle strategies, which are depicted in Figure 1.
The lifecycle strategies are identified by their simple average stock allocation over the 40 -year period. This is not a weighted average, and because portfolios will tend to be larger near retirement, the weighted average equity allocation will be less, but will differ for each simulation of asset returns. We construct eight lifecycles, namely "LC80", "LC70", "LC60",’LC50”, “LC40”, “LC30”, “LC20”, and "LC10". The two-digit number represents the approximate unweighted average equity exposure of that strategy. For instance, the "LC80" strategy has an average exposure to equities of 80.29 percent. Its exposure to equities is kept constant at 90 percent during the first 20 years, and then it drops in a linear fashion over the next 20 years to 53 percent at the retirement date. The exposures to equities in the "LC70", "LC60", "LC50", and "LC40" strategies are kept constant at 82.5 percent, 72 percent, 64 percent, and 50.5 percent for the first 20 years, and then decrease linearly to 36 percent, 26.5 percent, 12 percent, and 11.5 percent, respectively, over the final 20 years before retirement. The initial allocations to equities in the "LC30", "LC20", and "LC10" strategies are 50 percent, 41.5 percent, and 21 percent. In these cases, however, the decrease begins immediately to 11.5 percent, zero percent, and zero percent, respectively, by retirement.

We simulate 10,000 scenarios for each country. Each scenario consists of real returns for a particular country's two domestic assets over a 40-year period. For the bootstrap procedure, asset return data for each simulation are randomly drawn with replacement from the country's historical data. To fill each 40-year sequence, 40 years are chosen randomly with replacement from the historical data and the asset returns for each of those years is incorporated into the simulations. The simulated returns match the average returns, volatilities, and contemporaneous correlations present in the historical data. However, this re-sampling method does not capture any serial correlation present in each time series. The advantage of 
the bootstrap approach is that it is a multiperiod optimization procedure, which allows us to consider the asset allocation issue from a long-term perspective. Also, the bootstrap simulation procedure is non-parametric; it does not make any distributional assumptions about the normality of returns.

Allowing for diminishing marginal utility of wealth, the standard constant relative risk aversion [CRRA] utility function is used to compute the expected utility of wealth over the distribution of terminal wealth accumulations:

$$
\begin{array}{rlrl}
E\left[u\left(w_{i}\right)\right] & =\sum_{i=1}^{N}\left(\frac{1}{1-\gamma} w_{i}^{1-\gamma}\right) & & \text { for } \gamma>0, \gamma \neq 1 \\
& =\ln \left(w_{i}\right) \quad \text { for } \gamma=1
\end{array}
$$

where $w_{i}$ represents the wealth accumulation at retirement in each of $\mathrm{N}=10,000$ simulations. The variable $\gamma$ is the investor risk aversion, which we consider for a range from one to 10 . A value of zero represents risk neutrality, and increasingly positive values indicate increasing risk aversion. For our baseline case we consider a risk aversion coefficient of five (05) as representative of a relatively risk averse investor. We estimate the expected utility for each strategy across the spectrum of risk aversion coefficients by taking the mean utility from 10,000 simulations. The optimal portfolio strategy for each level of risk aversion is the strategy that provides investors with the highest expected utility. Accordingly, the portfolio strategies are ranked on the basis of the expected utility produced by each strategy for pension fund investors.

\section{DATA}

Data is available through the end of 2009 for all 25 countries. In order to avoid extremely high and low return outliers caused by hyperinflation, we consider the data since 1992 for Argentina and since 1995 for Brazil, in spite of the longer data availability for those countries. For all other countries, we use the longest time period in which all the relevant data could be collected. The starting dates do differ across the 25 countries though, ranging from 1988 to 1998 . Domestic equity returns are calculated by taking the annual percentage change at year end in local currency for the MSCI standard core gross indices for each country. For fixed income, we use bank deposit rates from the International Monetary Fund's International Financial Statistics [IMF IFS], except for a few cases in which data is collected from national sources. Also, for Pakistan, we use the call money rate as a proxy for its domestic deposit rate. To compute real returns, we use annual consumer price index data provided in the IMF IFS database.

Table 01 provides the time period covered for each country and the summary statistics of the relevant variables. For all the emerging market countries considered, except Poland where average returns are about the same, local stocks provide higher real returns with higher volatilities compared to local bank deposits. Correlations between the two assets are generally low, which implies the potential for diversification benefits.

\section{RESULTS}

Table 02 shows that, with two exceptions, for all of the risk aversion coefficients considered, a lifecycle strategy tends to provide higher utility than any fixed strategy except for cases in which either a fixed $100 / 0$ or fixed $0 / 100$ does better. An all-stock fixed strategy does provide higher expected utility for aggressive investors in some countries. A lifecycle strategy incorporating leverage could be devised in these cases. In Poland, as well, investors see little reason to invest in equities, and a fixed strategy with only bonds does perform best. Otherwise, for the most part, a lifecycle strategy provides higher expected utility for moderate and conservative investors. More conservative investors do tend to favor lifecycle strategies with lower average stock allocations. 
Table 03 provides a detailed ranking of expected utility for the 8 lifecycle and 11 fixed allocation strategies for an investor with risk aversion of five (5). All countries except Poland have a lifecycle strategy ranked first, and 12 of the 25 countries maximize expected utility with the LC30 strategy. As shown in Table 03, the best three portfolio choices out of 19 possibilities for pension fund investors in Chile, Czech Republic, Egypt, Peru, and Russia are lifecycle strategies. For all other countries but Poland, two of the best three choices are lifecycle strategies.

Moving to the last three rankings $\left[19^{\text {th }}\right.$, $\left.18^{\text {th }}, 17^{\text {th }}\right]$, the strategies "F100/0", "F90/10", and "F80/20," which are the most aggressive fixed strategies considered, respectively become the last three portfolio choices for the majority of emerging market pension funds. Also, the most conservative fixed strategies "F10/90" and "F0/100" are within the bottom three rankings for pension funds in Chile, Czech Republic, Mexico, Peru, and South Africa. When compared with fixed allocation strategies, lifecycle strategies provide the potential to ensure a higher level of welfare for emerging market pensioners.

As far as the pension funds in advanced economies are concerned, lifecycle funds are found to be one of the most emerging financial plans in the recent past. Our results further confirm that pension funds even in emerging market countries can also have benefits from lifecycle portfolio strategies which offer investors a chance to use time-varying portfolio mix, generally by declining equity exposure as the individual ages. Therefore, this simply implies that younger investors might hold a larger percentage of their total portfolio in stocks than older investors. This is rational because younger ones enjoy relatively greater flexibility in their future labor-supply decisions and thereby more tolerance of portfolio risk.

Further, lifecycle portfolio strategies are even more justifiable in emerging market context due to relatively higher volatility in stock markets. There are frequent short-term declines in emerging equity markets from which investors have to be protected near their retirement. It can be done by reducing the allocation to equities as the retirement approaches. Certain studies (Martellini \& Milhau, 2009) have argued that the lifecycle funds are better options for investors who have a little understanding on financial management (unsophisticated investors) because; they do not have to exert extra effort on making active portfolio selections. Moreover, lifecycle portfolio strategies are consistent with the standard target date funds due to the fact that equity returns are mean-reverting (equity returns come back to their long-run mean values). This implies that the optimal strategy requires a larger fraction of the portfolio in equities for the younger investors.

It should be noted that the bootstrapping simulation approach used in this study do account only for portfolio risk. Background risk that arises from various sources, including volatilities in labor income, real estate investments, and unanticipated expenses due to adverse health shocks is ignored when deciding investors' optimal portfolio allocations. In other words, our results are based on the assumption of market completeness. However, investors' behavior in choosing the optimal investment portfolio is impacted by various sources of background risk. Jiang et al. (2010) study how an investor's portfolio selection in a mean-variance framework is influenced by background risk. Accordingly, depending on the proportion of total wealth in assets which are exposed to background risk and the correlation of those assets with other financial assets, background risk shifts the efficient frontier to the right but keeps its initial shape. Also, as a result of background risk, the optimal portfolio consists of a hedge component in addition to the traditional mean-variance optimal portfolio by which background risk is hedged. Further, Heaton \& Lucas (2000) simulate the impact of 
background risk on an investor's portfolio choice using a calibrated dynamic model. They conclude that background risk emerges from cross-sectional differences in labor income, proprietary business risk, and ownership of employer's stocks. It results in reduced stock allocations in the optimal portfolio. In creating more appropriate investment policies for defined-contribution pension plans, shocks to the labor income stream over the investor's lifecycle and wealth accumulation can be key determinants (Bagliano et al., 2009). Therefore, in particular, the presence of independent background risk increases investor's risk aversion to portfolio risk and reduces the demand for other risky financial assets. Accordingly, if we had incorporated background risk into the current analysis, the optimal portfolio weights for risky assets like stocks would have been lower, depending on the extent to which background risk applies.

\section{CONCLUSION}

This study extends the current debate on lifecycle asset allocation strategies by considering their role for emerging market pension funds. The study justifies that emerging market retirement savers with varying attitudes toward risk can maximize their expected utility by using lifecycle strategies. Particularly, conservative pension fund investors tend to find one of the lifecycle strategies to be most suitable.

However, people may not behave in ways fully consistent with the expected utility framework used in this study. Future research should check the robustness of these findings by using alternative approaches recommended in behavioral finance to elicit member's utility functions. As argued by Vlaev et al. (2015), the effectiveness of financial advice services can significantly be improved by using the evidence from the behavioral sciences like Psychology. However, financial advisors are expected to adhere to certain ethical guidelines when applying knowledge of behavioral sciences to improve their financial advices.

Also, other factors like planned withdrawal rates during retirement and accessibility to other social security benefits should be taken into consideration. Subject to these limitations, we can conclude that the lifecycle approach has much to recommend it for retirement savers in emerging market countries.

\section{REFERENCES}

BALIANO FC, FUGAZZA C \& NICODANO G. Pension funds, Lifecycle asset allocation and Performance evaluation, OECD and World Bank sponsored project, Optimal Asset Allocation for Defined Contribution Mandatory Pension Funds. 2009; Available from: http://www.oecd.org/finance/privatepensions/43 779973.pdf (accessed on 23 July 2015).

BASU AK \& DREW ME. Portfolio Size Effect in Retirement Accounts: What Does it Imply for Lifecycle Asset Allocation Funds. The Journal of Portfolio Management. 2009;35: 61-72.

BASU AK, CHEN T \& CLEMENTS A. Are lifecycle funds appropriate as default options in participant-directed retirement plans? Economics letters. 2014; 124(1): 51-54

BURTLESS G. Lessons of the Financial Crisis for the Design of National Pension Systems. CESifo Economic Studies. 2010; 56(3): 323349.

FULLMER RK \& TZITZOURIS JA. Evaluating target-date glide paths for defined contribution plans. Investment risk and performance. 2014; Available from: http://www.cfapubs.org/doi/pdf/10.2469/irpn.v2 014.n1.7 (accessed on $5^{\text {th }}$ May, 2015). 
HEATON J \& LUCAS D. Portfolio Choice in the Presence of Background Risk, The Economic Journal. 2000; 110(460): 1-26

JIANG C, MA Y \& AN Y, An analysis of portfolio selection with background risk. Journal of Banking and Finance. 2010; 34: 3055-3060.

MARTELLINI L \& MILHAU V. Lifecycle funds need to be improved, The Financial Times 27 September. 2009; 10.

PFAU, WD. Lifecycle Funds and Wealth Accumulation for Retirement: Evidence for a More Conservative Asset Allocation as Retirement Approaches. Financial Services Review. 2010; 19 (1) : 59-74.

PFAU, WD. An Optimizing Framework for the Glide paths of Lifecycle Asset Allocation Funds. Applied Economic Letters. 2011; 18(1) : $55-58$.

SCHLEEF HJ \& EISINGER RM. Life-cycle funds: International Diversification, Reverse Glide Paths, and Portfolio Risk. Journal of Financial Planning. 2011; 24(1): 50-58.

VICEIRA LM. Pension fund design in developing economies. OECD working paper. Available from:

http://www.oecd.org/finance/privatepensions/43779987.pdf. (accessed on 23 July 2015).

VLAEV I, NIEBOER J, MARTIN S, \& DOLAN P. How behavioral science can improve financial advice services. Journal of Financial Services Marketing. 2015; 20: 74-88. 


\section{ANNEXURE}

Figure 01. Lifecycle portfolio strategies: Asset allocations over a 40-year career
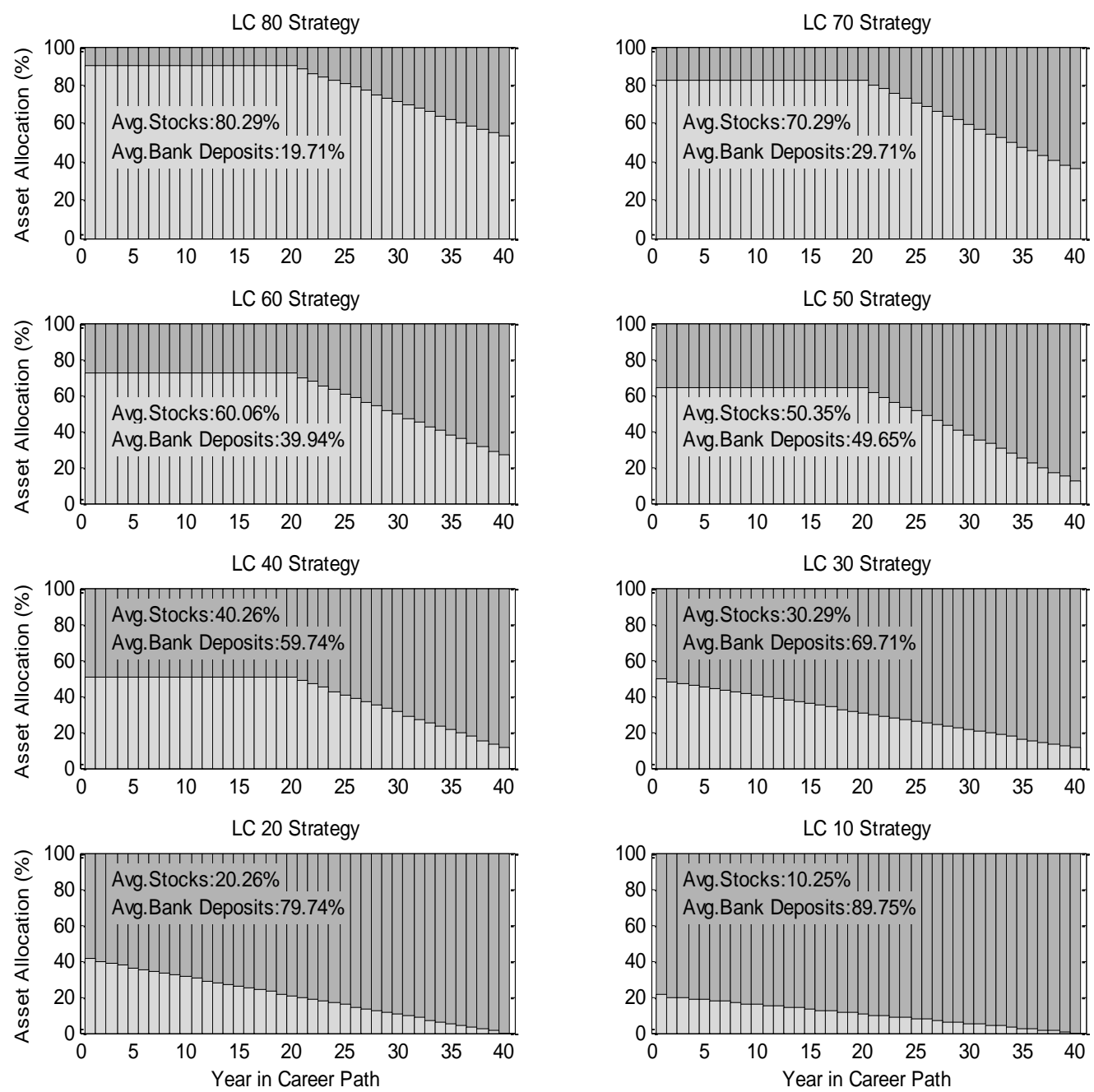
Bank Deposits Stocks

Source: Own calculation as explained in text. 
Table 01. Summary Statistics for Real Asset Returns in Emerging Market Countries (\%)

\begin{tabular}{|c|c|c|c|c|c|c|c|c|}
\hline \multirow[t]{2}{*}{ Country } & \multirow{2}{*}{$\begin{array}{c}\text { Start Year } \\
\text { (End } \\
\text { Year=2009) }\end{array}$} & \multicolumn{2}{|c|}{ Local Stocks } & \multicolumn{2}{|c|}{$\begin{array}{c}\text { Local Bank } \\
\text { Deposits }\end{array}$} & \multicolumn{2}{|c|}{ Inflation Rate } & \multirow{2}{*}{$\begin{array}{c}\text { Correlation } \\
\text { between } \\
\text { Local } \\
\text { Stocks and } \\
\text { Local Bank } \\
\text { Deposits }\end{array}$} \\
\hline & & Mean & Std & Mean & Std & Mean & Std & \\
\hline Argentina & 1992 & 11.5 & 37.8 & 3.6 & 6.4 & 7.2 & 8.1 & -0.15 \\
\hline Brazil & 1995 & 19.1 & 47.8 & 9.5 & 7.3 & 11.0 & 15.6 & 0.30 \\
\hline Chile & 1988 & 18.0 & 29.5 & 3.4 & 3.4 & 8.4 & 6.9 & -0.09 \\
\hline China & 1993 & 4.7 & 45.9 & -0.2 & 3.8 & 4.9 & 7.2 & 0.31 \\
\hline Columbia & 1993 & 18.7 & 41.3 & 4.4 & 3.4 & 11.6 & 7.2 & -0.59 \\
\hline Czech Rep. & 1995 & 11.7 & 30.4 & -1.0 & 1.6 & 4.5 & 3.4 & 0.56 \\
\hline Egypt & 1995 & 30.0 & 62.6 & 1.3 & 5.2 & 7.3 & 5.0 & 0.09 \\
\hline Hungary & 1995 & 18.4 & 47.6 & 0.8 & 2.6 & 10.4 & 7.6 & -0.23 \\
\hline India & 1993 & 13.9 & 39.8 & 1.2 & 2.6 & 6.8 & 3.0 & 0.04 \\
\hline Indonesia & 1988 & 23.9 & 67.2 & 4.6 & 5.9 & 11.2 & 11.1 & 0.09 \\
\hline Israel & 1993 & 8.9 & 30.1 & 2.8 & 2.8 & 5.0 & 4.3 & 0.34 \\
\hline Jordan & 1988 & 6.7 & 29.6 & 1.0 & 5.2 & 5.5 & 6.1 & 0.20 \\
\hline Korea & 1988 & 10.7 & 37.4 & 2.8 & 1.9 & 4.6 & 2.2 & 0.04 \\
\hline Malaysia & 1988 & 12.0 & 35.1 & 1.8 & 1.5 & 2.9 & 1.3 & 0.06 \\
\hline Mexico & 1988 & 18.6 & 34.6 & -1.2 & 7.1 & 17.7 & 23.7 & 0.26 \\
\hline Morocco & 1998 & 7.9 & 22.8 & 2.6 & 1.6 & 1.9 & 1.1 & -0.30 \\
\hline Pakistan & 1993 & 16.5 & 53.6 & 0.3 & 3.3 & 8.6 & 4.6 & 0.16 \\
\hline Peru & 1993 & 21.0 & 38.0 & -0.4 & 7.0 & 8.2 & 11.9 & 0.04 \\
\hline Philippines & 1988 & 10.8 & 44.1 & 1.7 & 2.4 & 7.4 & 3.6 & -0.08 \\
\hline Poland & 1994 & 2.0 & 34.3 & 2.1 & 2.2 & 9.4 & 9.9 & -0.14 \\
\hline Russia & 1995 & 14.4 & 60.0 & -9.9 & 11.5 & 34.2 & 49.4 & 0.19 \\
\hline S. Africa & 1993 & 10.4 & 22.8 & 3.7 & 2.4 & 6.9 & 2.5 & -0.06 \\
\hline Sri Lanka & 1993 & 12.7 & 55.8 & -0.1 & 4.1 & 10.3 & 4.7 & 0.45 \\
\hline Thailand & 1988 & 15.1 & 51.0 & 2.5 & 2.9 & 3.8 & 2.2 & 0.08 \\
\hline Turkey & 1988 & 39.1 & 120.6 & 2.0 & 8.4 & 52.1 & 31.2 & 0.04 \\
\hline
\end{tabular}

Source: Own calculations based on the historical economic data described in the "data" section. 
Table 02. Optimal Investment Strategies for Various Levels of Risk Aversion

\begin{tabular}{|l|c|c|c|c|c|c|}
\hline \multirow{2}{*}{ Country } & \multicolumn{5}{|c|}{ Risk Aversion Coefficient $(\gamma)$} \\
\cline { 2 - 7 } & $\mathbf{1}$ & $\mathbf{2}$ & $\mathbf{3}$ & $\mathbf{4}$ & $\mathbf{5}$ & $\mathbf{1 0}$ \\
\hline Argentina & LC80 & LC50 & LC30 & LC30 & LC30 & F10/90 \\
\hline Brazil & LC70 & LC40 & LC30 & LC20 & LC10 & LC10 \\
\hline Chile & F100/0 & F100/0 & LC80 & LC80 & LC70 & LC40 \\
\hline China & LC50 & LC30 & LC20 & LC10 & LC10 & F0/100 \\
\hline Columbia & F100/0 & LC70 & LC60 & LC40 & LC30 & LC30 \\
\hline Czech Rep. & F100/0 & F100/0 & LC80 & LC70 & LC60 & LC30 \\
\hline Egypt & F100/0 & LC70 & LC60 & LC40 & LC30 & LC20 \\
\hline Hungary & F100/0 & LC70 & LC60 & LC40 & LC40 & LC30 \\
\hline India & F100/0 & LC70 & LC50 & LC40 & LC30 & LC20 \\
\hline Indonesia & LC80 & LC50 & LC30 & LC30 & LC30 & LC20 \\
\hline Israel & F100/0 & LC60 & LC40 & LC30 & LC30 & LC10 \\
\hline Jordan & F100/0 & LC70 & LC50 & LC30 & LC30 & LC20 \\
\hline Korea & LC80 & LC50 & LC30 & LC30 & LC30 & F10/90 \\
\hline Malaysia & F100/0 & LC80 & LC60 & LC40 & LC30 & LC20 \\
\hline Mexico & F100/0 & F100/0 & F100/0 & LC80 & LC80 & LC60 \\
\hline Morocco & F100/0 & LC80 & LC70 & LC50 & LC40 & LC30 \\
\hline Pakistan & LC80 & LC60 & LC40 & LC30 & LC30 & LC20 \\
\hline Peru & F100/0 & F100/0 & LC80 & LC70 & LC60 & LC40 \\
\hline Philippines & LC80 & LC50 & LC30 & LC30 & LC30 & LC10 \\
\hline Poland & F0/100 & F0/100 & F0/100 & F0/100 & F0/100 \\
\hline Russia & LC70 8 & LC60 & LC50 & LC50 & LC40 \\
\hline South Africa & F100/0 & LC80 & LC60 & LC50 & LC30 \\
\hline Sri Lanka & LC60 & LC40 & LC30 & LC30 & LC10 \\
\hline Thailand & LC50 & LC30 & LC30 & LC20 & LC10 \\
\hline Nurkey & LC40 & LC30 & LC20 & LC20 & LC10 \\
\hline
\end{tabular}

Note: Lifecycle portfolio strategies are shaded.

Source: Own calculations as explained in text. 
Table 03. Ranking of Portfolio Strategies based on Expected Utility for Pension Fund Investors $(\gamma=5)$

\begin{tabular}{|c|c|c|c|c|c|c|c|c|c|c|c|c|c|c|c|c|c|c|c|}
\hline \multirow[t]{2}{*}{ Country } & \multicolumn{8}{|c|}{ Lifecycle Portfolio Strategies } & \multicolumn{11}{|c|}{ Fixed Portfolio Strategies } \\
\hline & $\begin{array}{c}\text { LC } \\
80 \\
\end{array}$ & $\begin{array}{c}\text { LC } \\
70 \\
\end{array}$ & $\begin{array}{r}\text { LC } \\
60 \\
\end{array}$ & $\begin{array}{c}\text { LC } \\
50\end{array}$ & $\begin{array}{r}\text { LC } \\
40 \\
\end{array}$ & $\begin{array}{c}\text { LC } \\
30\end{array}$ & $\begin{array}{c}\text { LC } \\
20 \\
\end{array}$ & $\begin{array}{c}\text { LC } \\
10 \\
\end{array}$ & $\begin{array}{c}F \\
100 / 0\end{array}$ & $\begin{array}{c}F \\
90 / 10\end{array}$ & $\begin{array}{c}F \\
80 / 20\end{array}$ & $\begin{array}{c}F \\
70 / 30\end{array}$ & $\begin{array}{c}F \\
60 / 40\end{array}$ & $\begin{array}{c}F \\
\mathbf{5 0 / 5 0}\end{array}$ & $\begin{array}{c}F \\
\mathbf{4 0 / 6 0}\end{array}$ & $\begin{array}{c}\mathbf{F} \\
30 / 70\end{array}$ & $\begin{array}{c}F \\
20 / 80\end{array}$ & $\begin{array}{c}F \\
10 / 90\end{array}$ & $\begin{array}{c}F \\
0 / 100\end{array}$ \\
\hline Argentina & 15 & 13 & 11 & 9 & 7 & 1 & 3 & 6 & & 18 & 17 & 16 & 14 & 12 & 10 & 5 & 2 & 4 & 8 \\
\hline Brazil & 16 & 13 & 12 & 10 & 8 & 6 & 3 & 1 & & 18 & 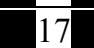 & 15 & 14 & 11 & 9 & 7 & 4 & 2 & 5 \\
\hline Chile & 3 & 1 & 2 & 6 & 10 & 13 & 16 & 18 & 14 & 11 & 8 & 7 & 4 & 5 & 9 & 12 & 15 & 17 & 19 \\
\hline China & 15 & 13 & 11 & 9 & 7 & 5 & 2 & 1 & & & & 16 & 14 & 12 & 10 & 8 & 6 & 3 & 4 \\
\hline Columbia & 15 & 12 & 8 & 5 & 2 & 1 & 7 & 11 & & & 5 & 16 & 13 & 9 & 4 & 3 & 6 & 10 & 14 \\
\hline Czech Rep. & 7 & 3 & 1 & 2 & 4 & 10 & 13 & 16 & & & 14 & 11 & 9 & 6 & 5 & 8 & 12 & 15 & 18 \\
\hline Egypt & 14 & 11 & 7 & 3 & 2 & 1 & 8 & 12 & & & & 15 & 13 & 9 & 6 & 4 & 5 & 10 & 16 \\
\hline Hungary & 15 & 11 & 7 & 4 & 1 & 2 & 8 & 12 & & 18 & 17 & 16 & 13 & 9 & 6 & 3 & 5 & 10 & 14 \\
\hline India & 15 & 12 & 8 & 5 & 2 & 1 & 6 & 10 & & & & 16 & 14 & 11 & 7 & 3 & 4 & 9 & 13 \\
\hline Indonesia & 15 & 13 & 11 & 8 & 7 & 1 & 2 & 6 & & & & 16 & 14 & 12 & 9 & 5 & 3 & 4 & 10 \\
\hline Israel & 15 & 13 & 11 & 8 & 6 & 1 & 2 & 7 & & $1 \varepsilon$ & & 16 & 14 & 12 & 10 & 5 & 3 & 4 & 9 \\
\hline Jordan & 15 & 13 & 10 & 7 & 3 & 1 & 4 & 8 & & 18 & & 16 & 14 & 12 & 9 & 5 & 2 & 6 & 11 \\
\hline Korea & 15 & 13 & 11 & 9 & 7 & 1 & 3 & 6 & & $\overrightarrow{18}$ & & 16 & 14 & 12 & 10 & 5 & 2 & 4 & 8 \\
\hline Malaysia & 15 & 12 & 8 & 4 & 2 & 1 & 7 & 11 & & 18 & 1 & 16 & 13 & 9 & 5 & 3 & 6 & 10 & 14 \\
\hline Mexico & 1 & 2 & 5 & 10 & 12 & 14 & 16 & 18 & & 7 & & 3 & 6 & 9 & 11 & 13 & 15 & 17 & 19 \\
\hline Morocco & 14 & 9 & 6 & 2 & 1 & 4 & 10 & 13 & & 18 & & 15 & 11 & 7 & 3 & 5 & 8 & 12 & 16 \\
\hline Pakistan & 15 & 13 & 11 & 8 & 4 & 1 & 2 & 7 & 19 & 18 & 17 & 16 & 14 & 12 & 9 & 6 & 3 & 5 & 10 \\
\hline Peru & 5 & 2 & 1 & 3 & 8 & 12 & 16 & 18 & 15 & 13 & 10 & 9 & 6 & 4 & 7 & 11 & 14 & 17 & 19 \\
\hline Philippines & 15 & 13 & 11 & 8 & 7 & 1 & 2 & 5 & 19 & 18 & 17 & 16 & 14 & 12 & 10 & 6 & 3 & 4 & 9 \\
\hline Poland & 15 & 13 & 11 & 9 & 8 & 6 & 4 & 2 & & 18 & 17 & 16 & 14 & 12 & 10 & 7 & 5 & 3 & 1 \\
\hline Russia & 14 & 8 & 4 & 1 & 2 & 3 & 10 & 12 & & 18 & 17 & 16 & 15 & 11 & 7 & 5 & 6 & 9 & 13 \\
\hline South Africa & 12 & 7 & 2 & 1 & 4 & 8 & 13 & 16 & & 117 & 14 & 11 & 9 & 5 & 3 & 6 & 10 & 15 & 18 \\
\hline Sri Lanka & 15 & 13 & 11 & 8 & 5 & 1 & 2 & 6 & 19 & 18 & 17 & 16 & 14 & 12 & 10 & 7 & 3 & 4 & 9 \\
\hline Thailand & 15 & 13 & 11 & 9 & 6 & 2 & 1 & 5 & 19 & 18 & 17 & 16 & 14 & 12 & 10 & 7 & 3 & 4 & 8 \\
\hline Turkey & 15 & 13 & 11 & 9 & 6 & 4 & 1 & 3 & 19 & 18 & 17 & 16 & 14 & 12 & 10 & 7 & 5 & 2 & 8 \\
\hline
\end{tabular}

Note: The rankings 1, 2, and 3 are shaded in gray color varieties and the rankings 17,18 , and 19 are shaded in black.

Source: Own calculations as explained in text. 